\title{
CANOPY COVER ESTIMATION FROM SATELLITE DATA FOR ACACIA MANGIUM PLANTATION BASAY, NEGROS ORIENTAL
}

\author{
F. A. M. Tandoc. ${ }^{1}$, C. J. S. Sarmiento ${ }^{1,2}$, E. C. Paringit ${ }^{1,2}$, A. M. Tamondong ${ }^{1,2}$, F. J. O. Pamittan ${ }^{1}$, R. A. G. Faelga ${ }^{1}$, \\ A. A. C. Maralit ${ }^{1}$, R. A. Lopez ${ }^{1}$, C. M. M. Arellano ${ }^{1}$, and C. Z. Vidad ${ }^{1}$. \\ ${ }^{1}$ Project DIME: Monitoring and Assessment of Planting Activities, University of the Philippines, Diliman, Quezon City 1101 \\ Philippines - tandoc.fe@gmail.com, fopamittan@up.edu.ph, reginefaelga@gmail.com, aeronadrianmaralit@gmail.com, \\ rusty.lpz@gmail.com, carlamae.arellano@gmail.com., and celeste.z.vidad@gmail.com \\ ${ }^{2}$ Department of Geodetic Engineering, University of the Philippines, Diliman Quezon City 1101 PHILIPPINES - \\ cssarmiento@up.edu.ph,paringit@gmail.com, and amtamondong@up.edu.ph
}

\section{Commission IV}

KEYWORDS: satellite images, forest inventory, forest monitoring, canopy cover

\begin{abstract}
:
Forest assessment and measurement can be costly, laborious and time-consuming when done manually. Remote Sensing aids by providing data of sufficient accuracy for large tracts of forest lands in the form of maps. These data can then assist in decision- making for better forest management. This study estimated canopy cover, a primary forest measurement parameter, using remotely- sensed data. Satellite images such as Planetscope and WorldView were used to estimate canopy cover. The results were then compared to measurements obtained from a manual inventory-in this case, of an Acacia mangium plantation. The manual inventory was conducted in a National Greening Program (NGP) site in Basay, Negros Oriental. Field inventory involved a Static Global Navigation Satellite System (GNSS) survey and a Total Station survey to get the accurate location of trees present in the plot. Diameter- at- breast was measured for all trees. Tree height and crown diameter were measured for at least 10 percent of all trees in the plot.
\end{abstract}

\section{INTRODUCTION}

The Philippines has $15,805,325$ hectares of forest lands (Philippine Forestry Statistics, 2017) providing various resources vital to human life. Given that the Philippines is a biodiversity hotspot, proper and sustainable forest management is imperative to protect and conserve Philippine forests. Various methods are used to be able to assess forests, may it be for extent, health, resources, and many others. Manual inventory and assessment of vast forest lands in hard to reach areas would obviously incur a lot of cost and effort, not to mention risks. With the use of satellite images, forest assessment could be done with lesser costs, effort and risks through remote sensing.

This study attempts such an act by estimating canopy cover with the use of satellite images such as Planetscope and WorldView.

\section{STUDY SITE}

\subsection{Location}

The selected study site is located at the Municipality of Basay, in the Province of Negros Oriental, Philippines. Basay is a fourth class municipality, 124 kilometers from the city of Dumaguete in Negros Oriental. The 125-hectare study site can be found in Barangay Cabatuanan, 224 meters above sea level. (Basay Negros oriental, 2019)

\subsection{Site Characteristics}

The study site is a 1.08-hectare plot within a 125-hectare Acacia mangium plantation. It was established in 2011 by the Cabatuanan Hill Tribes Association as part of the National Greening Program. The West part of the site have been replanted in the later years, and portions South of the site has been affected by landslides in 2014 . The site has $35 \%$ slope and a relatively rough terrain.

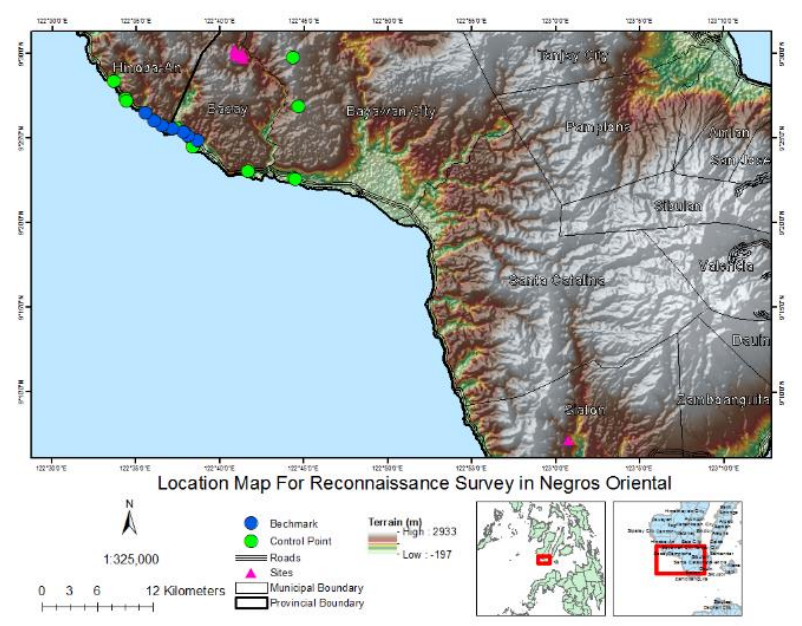

Figure 1. Location map of study site in Basay, Negros Oriental

\section{MATERIALS AND METHOD}

\subsection{Field data collection}

A reconnaissance survey was conducted in December 2018 to establish initial coordination with Local Government Units and with the Cabatuanan Hill Tribes Association. The reconnaissance was also necessary to see the conditions and characteristics of the area. Geodetic control points and benchmarks were also located. Information and initial assessment from the reconnaissance survey were used to strategize for the actual field validation survey. Field data collection was conducted on February 2019. 
3.1.1. GNSS Survey. The Static GNSS survey was done by using one Geodetic control point and one benchmark located at Barangay Bongalonan, 10.5 kilometers from the site and Barangay Poblacion, 10.2 kilometers from the site respectively. Using the reference points, two points were established in the study site. One in the North-West and one in the West as shown in Figure 2. A set of Trimble SPS 985 Global Positioning System was used for the Survey. Observations were done for 4 hours.

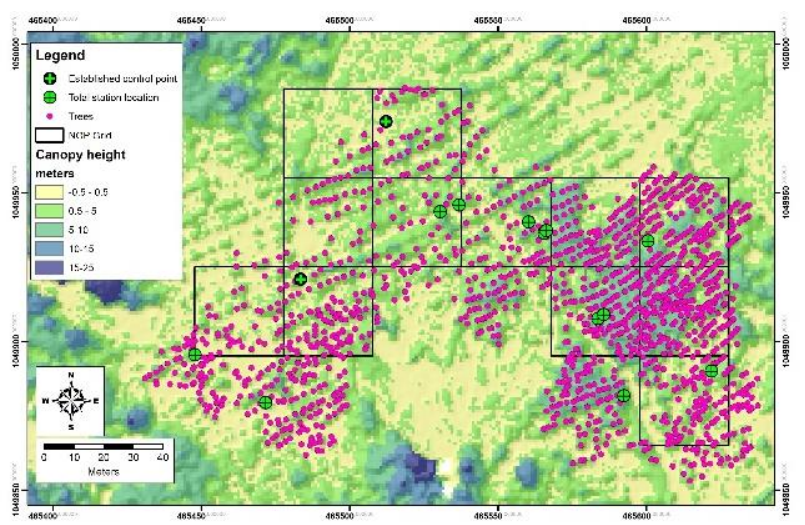

Figure 2. Survey points

3.1.2. Total Station Survey. Using the established points from the GNSS survey, the Total Station survey was done using two Total Stations. Stations are illustrated in Figure 2. Tree locations were obtained by taking sideshots and recording their corresponding tree numbers. The survey was done simultaneously with the manual tree inventory.

3.1.3. Manual Tree Inventory. To facilitate systematic tree inventory, the site was subdivided into sections of $30 \times 30$ meters. Each tree located within the $30 \times 30$ meter sections were measured. Inventory included numbering of trees using plastic labels. Trees were then measured for circumference at breast height or 1.3 meters from the ground (Manual of Forest Inventory, 1981) using tape measures these were then computed to obtain diameter values. Species identification was done with the assistance of locals, using local names. Locations were also recorded through the Total Station Survey. A total of 1416 trees were measured during the inventory as shown in Figure 2.

Crown diameter was measured for 157 trees from the manual inventory. The Acacia mangium trees measured were selected at random. This was done on the ground by locating the farthest tip of the crown from the North-South direction and measuring this with a meter tape, this was also done for the East-West direction. These measurements were then averaged to obtain the crown diameter and then computed for crown area. Figure 3 shows the crown area measured for the selected trees.

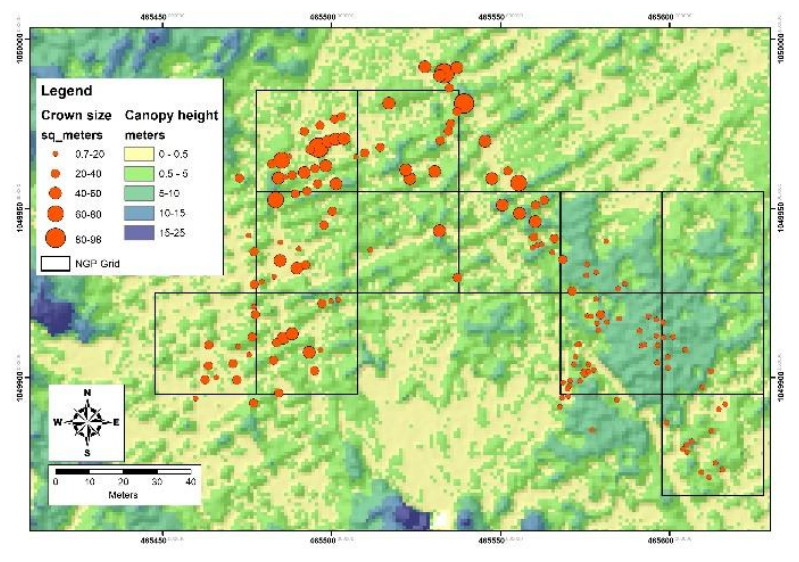

Figure 3. Crown area of 157 Acacia mangium trees

\subsection{Data Processing}

3.2.1. Field data. Field data measurements were organized per tree with the respective computation for diameter from circumference and crown diameter from averaged North-South and East-West measurements.

Simple linear regression from the 157 trees was used to develop a crown model for all the trees in the study site. The regression had an r-squared of 0.72 with the following crown model:

$$
c d=0.2763 x-0.3336
$$

where $\quad \mathrm{cd}=$ crown diameter

$\mathrm{x}=$ diameter at breast height

Using the crown model, the crown for all 1416 trees are visualized in Figure 4.

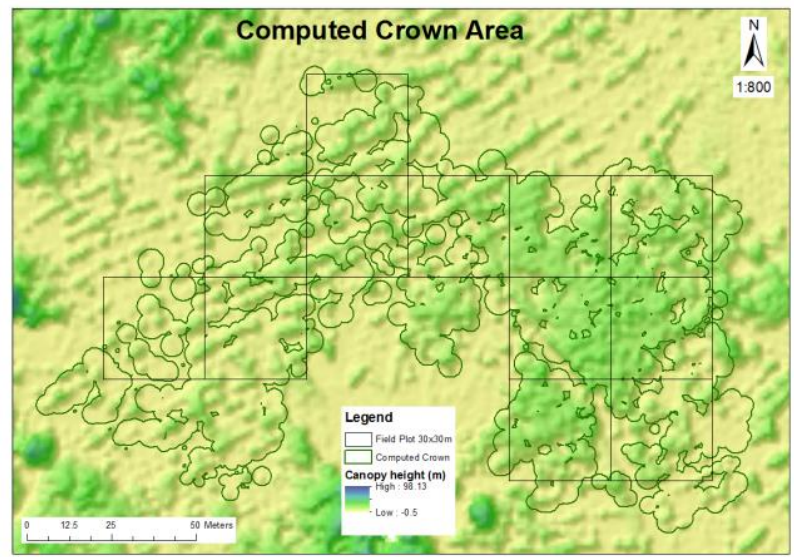

Figure 4. Computed crown area for all 1416 trees

The percent canopy cover was computed for each $20 \times 20$ meter grids and 10 x 10 meter grids using:

$$
\% \text { Canopy Cover }=\frac{\text { canopy area }}{\text { ground } \text { area }} \times 100 \%
$$


3.2.2. Satellite data: The images used are Planetscope captured on October 2018 and WorldView captured on January 2019. Images were preprocessed before it was used for cover analysis.

Pre-processing included georeferencing to ensure that the images overlayed properly with the site and measurements done on the field. This was done with ArcGIS georeferencing tool with Cubic Convolution Interpolation as the resampling method. The images then underwent radiometric or atmospheric correction to produce the surface reflectance image. This was done in ENVI using the QUick Atmospheric Correction (QUAC) Tool. The georeferenced-surface reflectance images are then processed in the Band Math tool of ENVI to adjust the reflectance values to a normal range (DIME-MAPA Terminal Report, 2019).

After preprocessing, the images are then processed for the computation of different vegetation indices namely: Normalized Difference Vegetation Index (NDVI), Soil-Adjusted Vegetation Index (SAVI) and, Modified Soil-Adjusted Vegetation Index (MSAVI). Canopy cover is then derived from the vegetation indices. Equations 3 to 5 show the computations for the vegetation indices, and Equations 6 to 8 show the computations for canopy cover.

$$
\begin{gathered}
N D V I=\frac{N I R-R E D}{N I R+R E D} \\
S A V I=\frac{N I R-R E D}{N I R+R E D+L}(1+L) \\
M S A V I=\frac{\left(2 \times N I R+1-\sqrt{(2 \times N I R+1)^{2}-8 \times(N I R-R E D)}\right)}{2} \\
\% C C=-4.337-3.733 \times N D V I \times 161.968 \times N D V I^{2} \\
\% C C=-22.634+180.38 \times S A V I-15.928 \times S A V I^{2} \\
\% C C=-1.9721+189.537 \times M S A V I-42 \times M S A V I^{2} \\
L=1-\frac{2 \times S \times(N I R-R E D) \times(N I R-S \times R E D)}{N I R+R E D}
\end{gathered}
$$

where $\quad$ NIR $=$ near infrared band

RED $=$ red band

$\mathrm{s}=$ slope of the soil line from a plot of RED versus NIR

The processed canopy cover from the images were then compared linearly with the computed canopy cover from the field validation survey.

\section{RESULTS AND DISCUSSION}

Table 1 summarizes the results of the linear regression between canopy cover from the field validation survey and from the vegetation index-derived cover at 10 x10 meter grids.

\begin{tabular}{|c|c|c|c|}
\hline Image & $\begin{array}{c}\text { NDVI Cover } \\
(10 \times 10 \mathrm{~m})\end{array}$ & $\begin{array}{c}\text { SAVI Cover } \\
(10 \times 10 \mathrm{~m})\end{array}$ & $\begin{array}{c}\text { MSAVI Cover } \\
(10 \mathrm{x} 10 \mathrm{~m})\end{array}$ \\
\hline Planetscope & 0.1623 & 0.1743 & 0.0417 \\
\hline WorldView & 0.0737 & 0.052 & 0.1413 \\
\hline
\end{tabular}

Table 1. R-squared values of field versus vegetation indexderived cover at $10 \times 10$ meter grids
Table 2 summarizes the results of the linear regression between canopy cover from the field validation survey and from the vegetation index-derived cover at $20 \times 20$ meter grids.

\begin{tabular}{|c|c|c|c|}
\hline Image & $\begin{array}{c}\text { NDVI Cover } \\
(20 \times 20 \mathrm{~m})\end{array}$ & $\begin{array}{c}\text { SAVI Cover } \\
(20 \times 20 \mathrm{~m})\end{array}$ & $\begin{array}{c}\text { MSAVI Cover } \\
(20 \times 20 \mathrm{~m})\end{array}$ \\
\hline Planetscope & 0.0064 & 0.006 & 0.0297 \\
\hline WorldView & 0.0236 & 0.0149 & 0.0042 \\
\hline
\end{tabular}

Table 2. R-squared values of field versus vegetation indexderived cover at $20 \times 20$ meter grids

This study does not show promising results in terms of r-squared values or relation of field measured cover and vegetation indexderived cover. The main reason that could explain the weak relationship between the two values is the presence of undergrowth or low -lying vegetation. This is not accounted for in the measurement of canopy cover in the field. This undergrowth is included in the computation of vegetation indices which in turn is accounted for in the canopy cover. This would also explain the presence of outliers in the linear regression, since some grids would have no canopy cover from the field but will have values from the vegetation index-derived canopy cover.

\section{CONCLUSION}

Accurately estimating canopy cover from vegetation indices would be very difficult if sites or forest areas have thick undergrowth or low-lying vegetation. The reason for this is that vegetation indices tend to overestimate canopy cover due to the presence of forest undergrowth.

\section{REFERENCES}

Basay - Negros Oriental. (2019). Retrieved from https://dumaguete.com/basay-negros-oriental/

Digital Imaging for Monitoring and Evaluation - Monitoring and Assessment of Planting Activities and Other Applications (DIME-MAPA2) Terminal Report. (2019). University of the Philippines - Diliman, Philippines.

Lockhart, B. R., Weih, R. C. Jr., and Smith, K. M. (2005). Crown Radius and Diameter at Breast Height Relationships for Six Bottomland Hardwood Species. Journal of the Arkansas Academy of Science, Vol. 59, pp. 110-115

Manual of Forest Inventory. (1981). FAO Forestry Paper. Food and Agriculture Organization of the United Nations. Rome

Purevdori, T., Tateishi, R., Ishiyama, T., and Honda, Y. (1998). Relationships Between Percent Vegetation Cover and Vegetation Indices, International Journal of Remote Sensing, Vol.18, pp. 3519-3535

Philippine Forestry Statistics (2017). Forest Management Bureau. Department of Environment and Natural Resources 